\title{
Vein graft arterialization causes differential activation of mitogen-activated protein kinases
}

Paul C. Saunders, MD

Giuseppe Pintucci, PhD

Costas S. Bizekis, MD

Ram Sharony, MD

Kevin M. Hyman, MD

Fiorella Saponara, BA

F. Gregory Baumann, PhD

Eugene A. Grossi, MD

Stephen B. Colvin, MD

Paolo Mignatti, MD

Aubrey C. Galloway, MD
From the Seymour Cohn Cardiovascular Research Laboratory, Division of Cardiothoracic Surgery, Department of Surgery, New York University School of Medicine, New York, NY.

This work was supported by funds from the Seymour Cohn Foundation for Cardiovascular Surgery Research.

Received for publication April 4, 2003; revisions requested June 2, 2003; revisions received July 30, 2003; accepted for publication July 31, 2003.

Address for reprints: Aubrey C. Galloway, MD, Professor of Surgery, Director, Cardiac Surgical Research, New York University School of Medicine, 530 First Ave, Suite 9V, New York, NY 10016 (E-mail: galloway@cv.med.nyu.edu).

J Thorac Cardiovasc Surg 2004;127:1276-84 $0022-5223 / \$ 30.00$

Copyright () 2004 by The American Association for Thoracic Surgery

doi:10.1016/j.jtcvs.2003.07.017
Objective: Vascular injury results in activation of the mitogen-activated protein kinases-extracellular-signal regulated kinases, c-jun N-terminal kinase, and p38 $8^{\mathrm{MAPK}}$ — which have been implicated in cell proliferation, migration, and apoptosis. The goal of this study was to characterize mitogen-activated protein kinase activation in arterialized vein grafts.

Methods: Carotid artery bypass using reversed external jugular vein was performed in 29 dogs. Vein grafts were harvested after 30 minutes and 3, 8, and 24 hours, and $4,7,14$, and 28 days. Contralateral external jugular vein and external jugular vein interposition vein-to-vein grafts were used as controls. Vein graft extracts were analyzed for extracellular-signal regulated kinases, c-jun $\mathrm{N}$-terminal kinase, and $\mathrm{p} 38^{\mathrm{MAPK}}$ activation. Proliferating cell nuclear antigen expression was investigated as a parameter of cell proliferation. Apoptosis was assessed by terminal deoxynucleotidyl transferase-mediated 2'-deoxyuridine 5'-triphosphate nick end labeling staining and intimal hyperplasia by morphometric examination of tissue sections.

Results: Significant intimal hyperplasia was observed at 28 days. Over the time points studied, vein graft arterialization resulted in bimodal activation of both extracellularsignal regulated kinase and $\mathrm{p} 38^{\mathrm{MAPK}}$ (30 minutes through 3 hours; 4 days) but did not induce activation of c-jun $\mathrm{N}$-terminal kinase. Proliferating cell nuclear antigen expression increased from days 1 through 28, and apoptosis increased between 8 and 24 hours.

Conclusion: Vein graft arterialization induces bimodal activation of extracellular-signal regulated kinase and $\mathrm{p} 38^{\mathrm{MAPK}}$; however, in contrast with what is described in arterial injury, it does not induce c-jun N-terminal kinase activation. These results provide the first comprehensive characterization of the mitogen-activated protein kinase signaling pathways activated in vein graft arterialization and identify mitogen-activated protein kinases as potential mediators of vein graft remodeling and subsequent intimal hyperplasia.

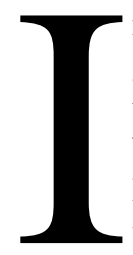

ntimal hyperplasia is a major impediment to long-term patency of autologous vein grafts in cardiac and peripheral vascular bypass surgery. ${ }^{1} \mathrm{Al}-$ though vein grafts are the most widely used conduits for coronary artery bypass grafting (CABG), their ultimate success is limited by high rates of late stenosis and eventual luminal occlusion. Recent reports show $10 \%$ of vein grafts to be thrombosed within 60 days after CABG and only $50 \%$ of grafts to be patent at 10 years. ${ }^{2,3}$ By 1 year after CABG, intimal hyperplasia is 

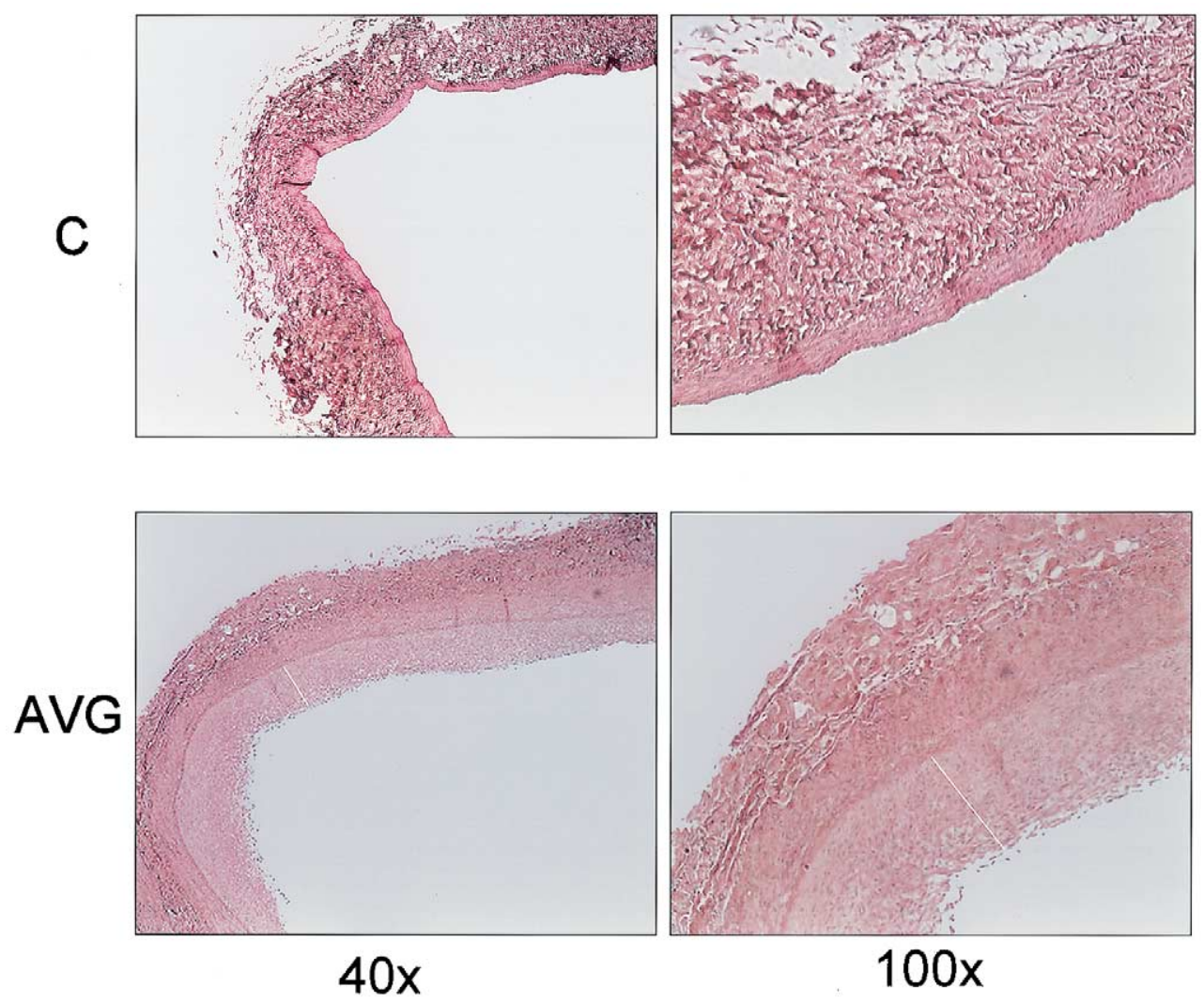

Figure 1. Vein graft arterialization results in intimal hyperplasia. Representative hematoxylin and eosin-stained contralateral external jugular vein (C) and arterialized vein graft (AVG) at 28 days. White lines identify intimal hyperplasia. $(40 \times, 100 \times$.)

found, to some degree, in all grafts. ${ }^{3}$ Late graft failure has a significant clinical impact, resulting in recurrent ischemia and angina, myocardial infarction, limb loss, reoperation, and even death. ${ }^{2}$

The development of intimal hyperplasia in the arterialized vein graft is characterized by uncontrolled proliferation and migration of medial smooth muscle cells into the intima and massive deposition of interstitial collagen. ${ }^{1,2,4}$ The response to both mechanical injury and shear stress resembles that observed in injured arteries after balloon angioplasty and, more generally, recalls key early events in atherogenesis. ${ }^{5}$ However, the signaling pathways that mediate these changes and ultimately lead to the formation of neointima remain unclear. ${ }^{6}$

Cells respond to external stimuli by activation of intracellular signaling pathways, which can be mediated by membrane receptors. ${ }^{7}$ When a signal is transmitted to the nucleus through a cascade of signal transduction molecules, the mitogen-activated protein kinases (MAPKs) act as the ultimate mediators of extracellular stimuli between the cytoplasm and the nucleus. ${ }^{7}$ Whereas MAPKs can phosphorylate cytoplasmic substrates, in the nucleus they activate transcription of specific genes by modulating a variety of transcription factors. ${ }^{7}$ The 3 major subgroups of the MAPK family are the extracellular signal-regulated kinases (ERK-1/2), c-jun N-terminal kinases (JNKs), and $\mathrm{p} 38^{\mathrm{MAPK}}$. Both the integration of these pathways and their kinetics of activation determine cellular behavior and fate. ${ }^{8}$

Numerous data obtained with cultured vascular endothelial or smooth muscle cells and with injured arteries link MAPK activation to cell proliferation, migration, and apoptosis. ${ }^{9-11}$ Both the ERK-1/2 and JNK pathways are activated with different kinetics in balloon-injured arteries, and their inhibition results in decreased medial cell proliferation and intimal hyperplasia. ${ }^{6,12,13}$ Although vein grafts remain of central importance in cardiac and peripheral vascular surgery, the literature on MAPK activation in vein interposition grafts is limited. In addition, vein graft arterialization generates distinctly different stimuli from those induced by arterial injury following balloon angioplasty and/or stent implantation. ${ }^{5,14,15}$ In this study, we used a canine model of carotid artery bypass to characterize MAPK activation in arterialized vein grafts. 

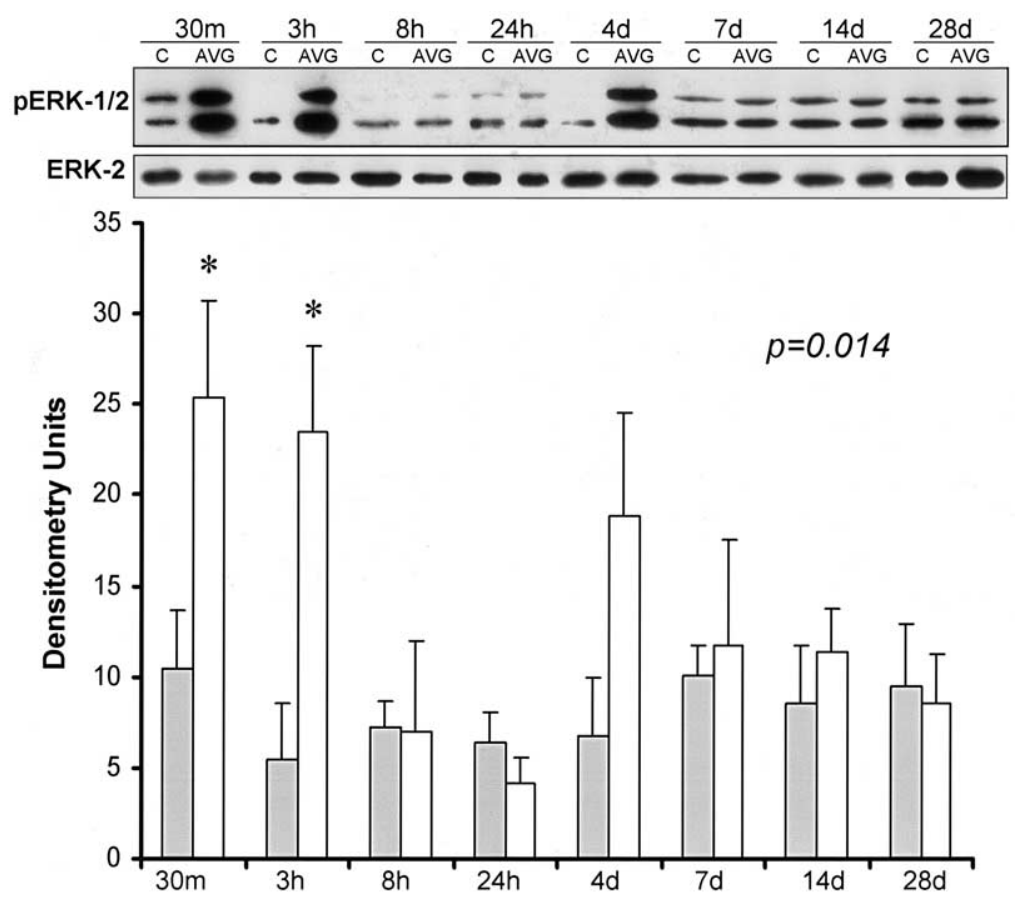

Figure 2. Vein graft arterialization induces bimodal ERK-1/2 activation. Representative Western blot comparing ERK-1/2 activation in contralateral external jugular vein (C) and arterialized vein graft (AVG) at the indicated time points after arterialization. Upper panel: membranes probed with anti-phospho-ERK-1/2 antibody (pERK-1/2); lower panel: membranes probed with anti-ERK-2 antibody (ERK-2). Densitometric analysis of ERK-1/2 activation in contralateral external jugular veins (gray bars) and arterialized vein grafts (white bars). Means \pm SEM of 3 independent experiments are shown. Overall statistical significance is shown. Asterisk denotes significant difference from the control at each time point $(P<.05)$ via GLM parameter estimates.

\section{Methods}

\section{Operative Procedure}

Carotid artery bypass using reversed autologous external jugular vein (EJV) was performed on 29 purpose-bred adult mongrel dogs $(\sim 25 \mathrm{~kg})$. The animals were premedicated with atropine 0.05 $\mathrm{mg} / \mathrm{kg}$ IV and anesthetized with ketamine $10 \mathrm{mg} / \mathrm{kg}$ IV and diazepam $0.5 \mathrm{mg} / \mathrm{kg}$ IV. The dogs were ventilated via endotracheal tube with $100 \%$ oxygen and maintained under anesthesia with $1.5 \%$ to $2.0 \%$ isoflurane in oxygen at $2 \mathrm{~L} / \mathrm{min}$.

A midline neck incision was made from the thyroid cartilage to the sternal notch and the EJV was exposed with a "no-touch" technique, and side branches were clipped and divided. After heparinization $(100 \mathrm{U} / \mathrm{kg})$, the ipsilateral common carotid artery was dissected free and the EJV was ligated, excised, and then flushed (but not distended) with plasmalyte solution. A segment of the excised vein was removed and labeled "control 1" (C1). The vein was grafted to the carotid artery with end-to-side vascular anastomoses, performed with standard vascular surgical techniques and 7-0 polypropylene suture, and the carotid artery was ligated and divided. The wound was closed in 2 layers.

At the time of death, the dogs were anesthetized as described above. Carotid artery and interposition vein graft were exposed through the previous incision. As a control, a segment of contralateral EJV was mobilized and excised. A 5-mm section was fixed in formaldehyde $(3.7 \%)$ for subsequent histologic examination, and the remainder was placed in lysis buffer (see below) and labeled "control 2" (C2). An arteriotomy was made in the carotid distal to the vein graft to confirm its patency. After perfusion with plasmalyte solution, the arterialized vein graft was excised and a 5-mm segment from the midportion of the vein graft was fixed in formaldehyde $(3.7 \%)$ for subsequent histologic examination. The remainder was placed in lysis buffer (see below) and labeled "sample 3" (S3). Animals were killed using a commercially available euthanasia solution containing pentobarbital.

All vein grafts were patent at time of harvest, and all operations were performed without a fatality. Vein grafts were harvested at each of the following time points: 30 minutes; 3, 8, and 24 hours; and $4,7,14$, and 28 days $(n=3)$. These times were chosen to monitor the rapid activation of intracellular signaling, cell proliferation, and programmed death (apoptosis) and the early stages of development of intimal hyperplasia. When veins were harvested $\leq 3$ hours after surgery, the animals were maintained under anesthesia; all others were allowed to recover.

As further controls, 3 dogs underwent vein-to-vein bypass using an EJV vein graft to the contralateral EJV, and 2 dogs underwent artery-to-artery bypass using a carotid artery graft to the contralateral carotid artery. Harvested femoral vein and artery were used as controls for the MAPK activation assays. 

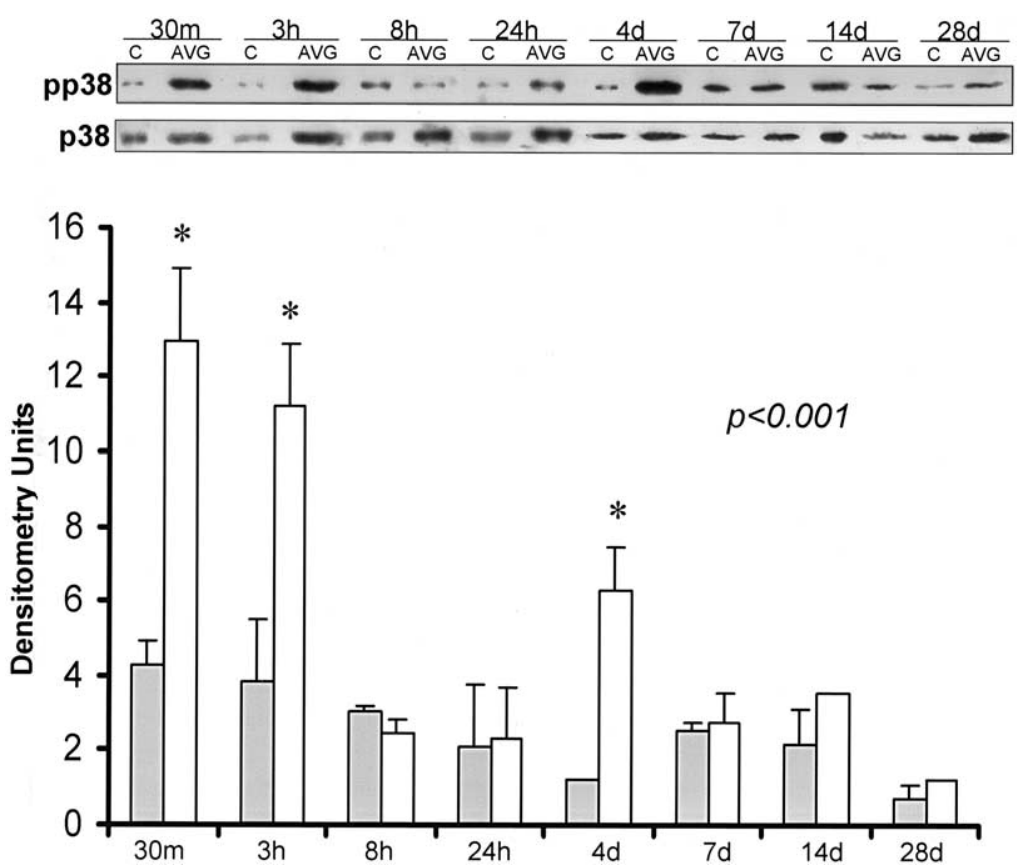

Figure 3. Vein graft arterialization induces bimodal p38 $^{\text {MAPK }}$ activation. Representative Western blot comparing p38 $^{\text {MAPK }}$ activation in contralateral external jugular vein (C) and arterialized vein graft (AVG) at the indicated time points after arterialization. Upper panel: membranes probed with anti-phospho-p38MAPK antibody (p38); lower panel: membranes probed with anti-ERK-2 antibody (pp38). Densitometric analysis of p38 $^{\text {MAPK }}$ activation in contralateral external jugular veins (gray bars) and arterialized vein grafts (white bars). Means \pm SEM of 3 independent experiments are shown. Overall statistical significance is shown. Asterisk denotes significant difference from the control at each time point $(P<.05)$ via GLM parameter estimates.

These procedures conformed with the Guide for the Care and Use of Laboratory Animals published by the US National Institutes of Health (NIH Publication no. 85-23, revised 1996) and were approved by the Institutional Animal Care and Use Committee.

\section{Sample Processing}

Immediately after excision, samples were harvested and processed as previously described. ${ }^{15}$ A segment of each sample was removed and fixed in $3.7 \%$ formaldehyde for hematoxylin and eosin staining and immunohistochemical analysis.

\section{Western Blotting}

Equal amounts of vein extract protein $(20-60 \mu \mathrm{g})$ were electrophoresed in sodium dodecyl sulfate $/ 10 \%$ polyacrylamide gels and blotted onto polyvinylidene fluoride (PVDF) membranes (Millipore, Bedford, Mass). The membranes were incubated with antibodies to the active (phosphorylated) forms of either ERK-1/2 or p38 ${ }^{\text {MAPK }}$ (Cell Signaling Technology, Beverly, Mass). As a control for equal loading and transfer, the membranes were stripped and reprobed with antibodies to the total form of the corresponding signaling protein (anti-ERK-2, anti-p38 ${ }^{\text {MAPK }}$ antibodies, Santa Cruz Biotechnology, Inc, Santa Cruz, Calif). To study activation of the JNK pathway, we used an in vitro kinase assay that detects phosphorylation of a glutathione S-transferase (GST)-Jun fusion protein by means of a pull-down assay in which c-Jun is both the bait and the substrate for JNK (Cell Signaling Technology). As a control for equal loading and transfer, the membranes were stripped and reprobed with anti-total c-Jun antibody (Cell Signaling Technology). The membranes were incubated with horseradish peroxidase-labeled anti-rabbit immunoglobulin $\mathrm{G}$ antibodies (Amersham Pharmacia Biotech, Inc, Piscataway, NJ), and antigenantibody complexes were detected by enhanced chemiluminescence (Lumilight, Roche, Indianapolis, Ind).

Quantitative analysis of the immunoreactive bands was performed by scanning densitometry with Kodak 1D Image Analysis software (Kodak, Rochester, NY). The active forms of each protein were normalized to the total amount of the corresponding protein, and kinase activity was measured in arterialized vein grafts compared with contralateral EJVs.

\section{Histologic and Immunohistochemical Analysis}

Cross sections (4-6 $\mu \mathrm{m}$ ) of fixed vein segments were stained with hematoxylin and eosin for morphologic examination or Van Gieson stain to visualize the elastic fibers. For immunodetection of active MAPKs, paraffin-embedded sections were processed with the ABC staining kit (Santa Cruz Biotechnology, Inc) using the anti-active MAPK antibodies described above, except that phospho-p38 $8^{\text {MAPK }}$ monoclonal antibody (Cell Signaling Technology) was used. Sections were also immunostained for $\alpha$-smooth muscle actin ( $\alpha$-SMA) using a specific monoclonal antibody (Sigma, St Louis, Mo). 


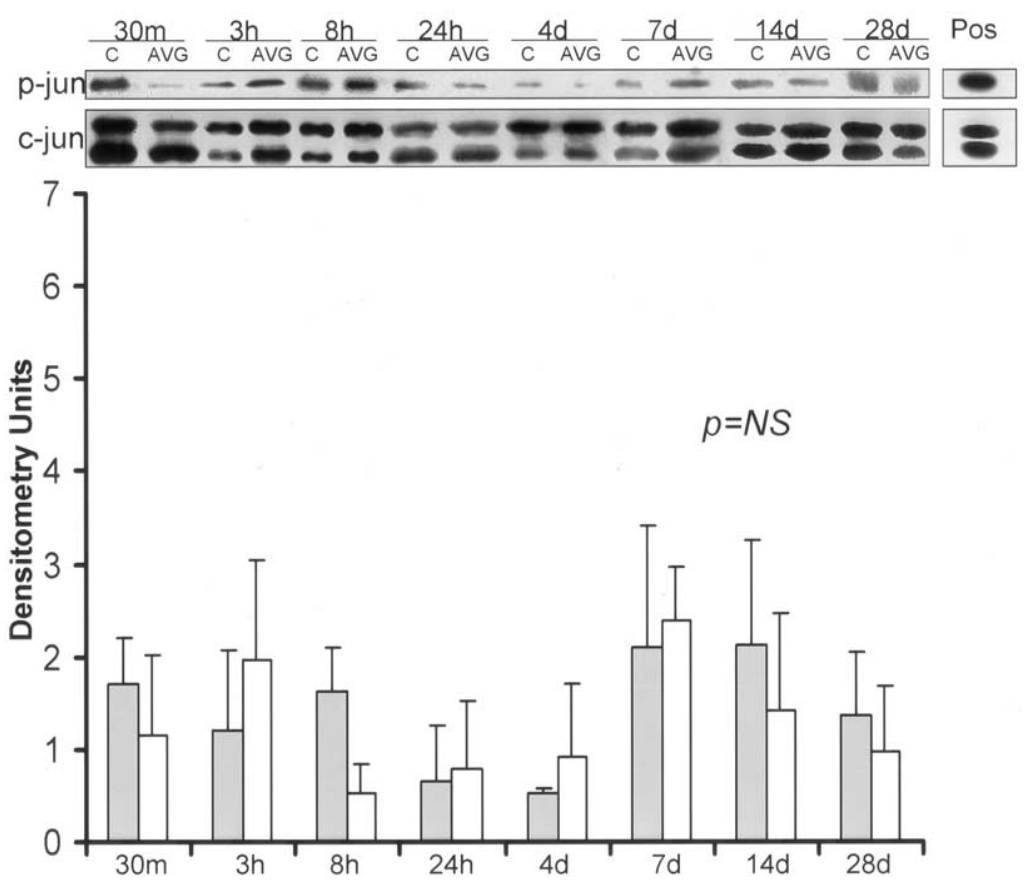

Figure 4. Vein graft arterialization does not induce JNK activation. Representative Western blot of in vitro kinase reaction products comparing JNK activation in contralateral external jugular vein $(C)$ and arterialized vein graft (AVG) at the indicated time points after arterialization. Upper panel: membranes probed with anti-phospho-jun antibody (p-jun); lower panel: membranes probed with anti-c-jun antibody (c-jun). Positive control (Pos) was obtained by lysing Madin-Darby canine kidney (MDCK) cells 10 minutes after irradiation with $20 \mathrm{~mJ} / \mathrm{cm}^{2}$ of UV-C. Densitometric analysis of JNK activation in contralateral external jugular veins (gray bars) and arterialized vein grafts (white bars). Means \pm SEM of 3 independent experiments are shown. Overall statistical significance is shown.

\section{Cell Proliferation and Apoptosis}

To monitor cell proliferation, expression of proliferating cell nuclear antigen (PCNA), a $36-\mathrm{kDa}$ protein that accumulates in the nucleus of cells committed to overcome the G1 phase of the cell cycle, was analyzed by Western blotting of vein graft extracts using monoclonal antibodies to PCNA (LabVision, Fremont, Calif). Lysates of proliferating endothelial cells were used as a positive control for PCNA expression. Detection of antigen-antibody complexes and scanning densitometry were performed as described above. For immunohistochemical detection of PCNA, paraffin-embedded sections of the vein samples were analyzed with the same antibodies used for Western blotting.

To detect apoptotic cells, cross sections (4-6 $\mu \mathrm{m}$ ) of paraffinembedded vein segments were stained for ladderized DNA using the terminal deoxynucleotidyl transferase-mediated 2'-deoxyuridine 5'-triphosphate nick end labeling (TUNEL) assay (Oncogene Research Products, Boston, Mass). The sections were counterstained with the nuclear stain Hoechst 33342 and analyzed with a fluorescence microscope (Zeiss Axioskop 2, Carl Zeiss, Inc, Thornwood, NY).

\section{Statistical Analysis}

The results were analyzed using the SPSS statistical software package (version 11; Chicago, Ill). Analysis of variance via a general linear model (GLM) was used to analyze overall differ- ences of the effects of time and treatment; parameter estimates were used for comparison between groups at each time point. Results are expressed as mean \pm standard error of the mean, unless otherwise stated.

\section{Results}

Vein Graft Arterialization Produces Vascular Injury, Remodeling, and Intimal Hyperplasia Interposition vein graft bypass of the carotid artery using reversed EJVs produced a characteristic series of histologic changes over 28 days. Early signs of endothelial sloughing were accompanied by lining of the luminal surface with leukocytes and leukocytic invasion of the vein wall. By 1 to 4 days, the vein grafts became dilated and showed edema and occasional hemorrhage in the media, and by 1 week, small areas of intimal hyperplasia could be observed (data not shown). By 28 days these areas evolved into eccentric lesions that encroached into the vein graft lumen (Figure 1).

MAPK Pathways Are Activated in a Bimodal Manner Following Vein Graft Arterialization

Arterialization of reversed EJV grafts resulted in activation of ERK-1/2 30 minutes after anastomosis, with stronger 

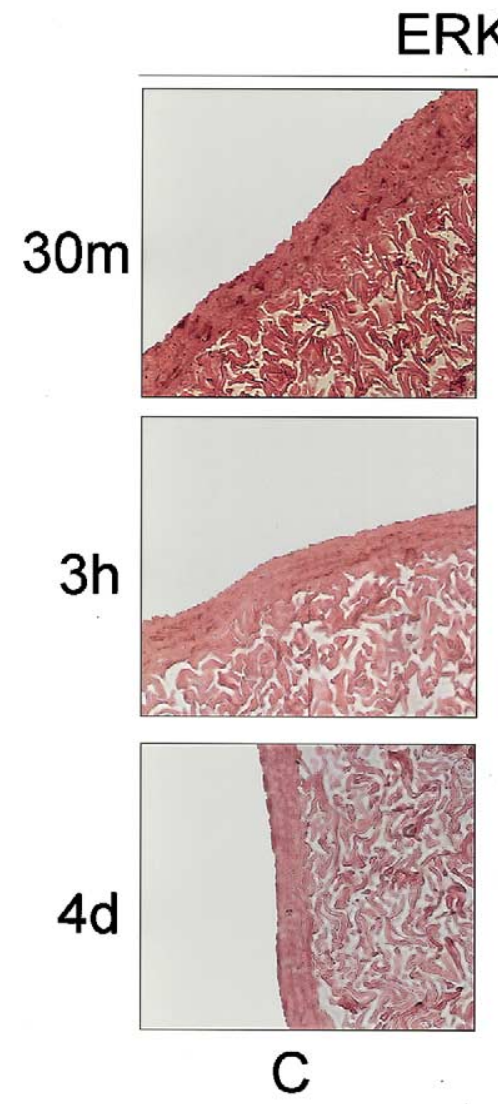
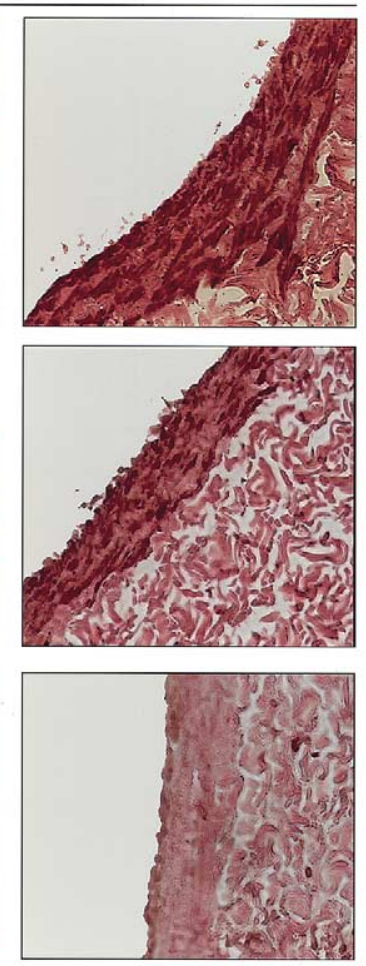

AVG
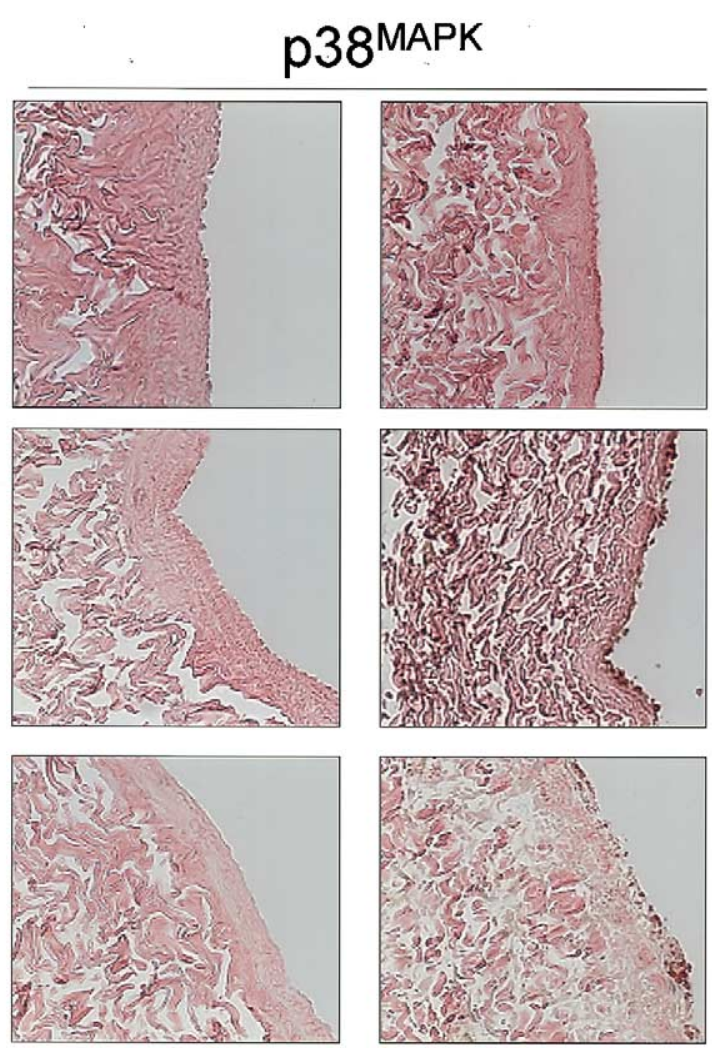

C

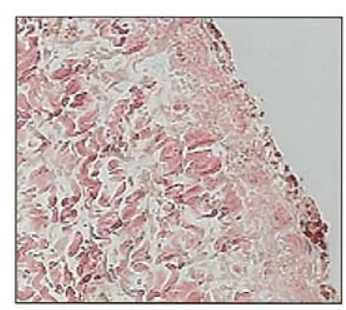

AVG

Figure 5. ERK-1/2 and p38 ${ }^{\mathrm{MAPK}}$ activation occurs in medial and luminal cells after vein graft arterialization. Immunohistochemical staining of contralateral external jugular vein (C) and arterialized vein graft (AVG) with anti-phospho-ERK-1/2 antibody and anti-phospho-p38 ${ }^{\text {MAPK }}$ antibody. $(400 \times$.

activation occurring at 3 hours. A second peak of ERK-1/2 activation was observed at 4 days (although not statistically significant), after which ERK-1/2 activation decreased toward control levels (Figure 2). Vein graft arterialization also resulted in strong activation of $\mathrm{p} 38^{\mathrm{MAPK}}$ at 30 minutes and 3 hours (Figure 3 ). A second peak of activation was observed at 4 days.

Preliminary attempts to investigate the JNK pathway by using phospho-specific antibodies failed to yield consistent results (data not shown). Therefore, we chose a more sensitive in vitro kinase assay that detects phosphorylation of c-jun, a specific JNK substrate. Unlike ERK-1/2 and $\mathrm{p} 38^{\mathrm{MAPK}}$, vein graft arterialization did not result in consistent JNK activation (Figure 4).

Confirming the Western blotting results, immunohistochemical analysis of arterialized vein grafts showed active ERK-1/2 and $\mathrm{p} 38^{\mathrm{MAPK}}$ associated with $\alpha$-SMA positive cells at 30 minutes, 3 hours, and 4 days (Figure $5)$.

\section{Vein Graft Arterialization Induces Both Medial Cell Proliferation and Apoptosis}

To characterize the effect of vein arterialization on cell proliferation, we analyzed PCNA expression by Western blotting. As shown in Figure 6, A, no induction of PCNA expression was detected at 30 minutes, 3 hours, or 8 hours. At 24 hours, a modest induction of PCNA expression was observed in arterialized vein grafts as compared with controls. Subsequently, an 8- to 14-fold increase of PCNA expression over control levels was detected from 4 days to 28 days. Immunohistochemical analysis confirmed these findings, with strong staining for PCNA in the inner media and neointima (Figure 6, B).

Because apoptosis has been shown to occur after vein graft arterialization in a swine model, ${ }^{16}$ we investigated whether programmed cell death also occurs in our model. As shown in Figure 6, $C$, TUNEL assay of sections of arterialized vein grafts and contralateral EJV showed apoptosis in the inner media at 8 hours and 24 hours after arterialization, whereas 

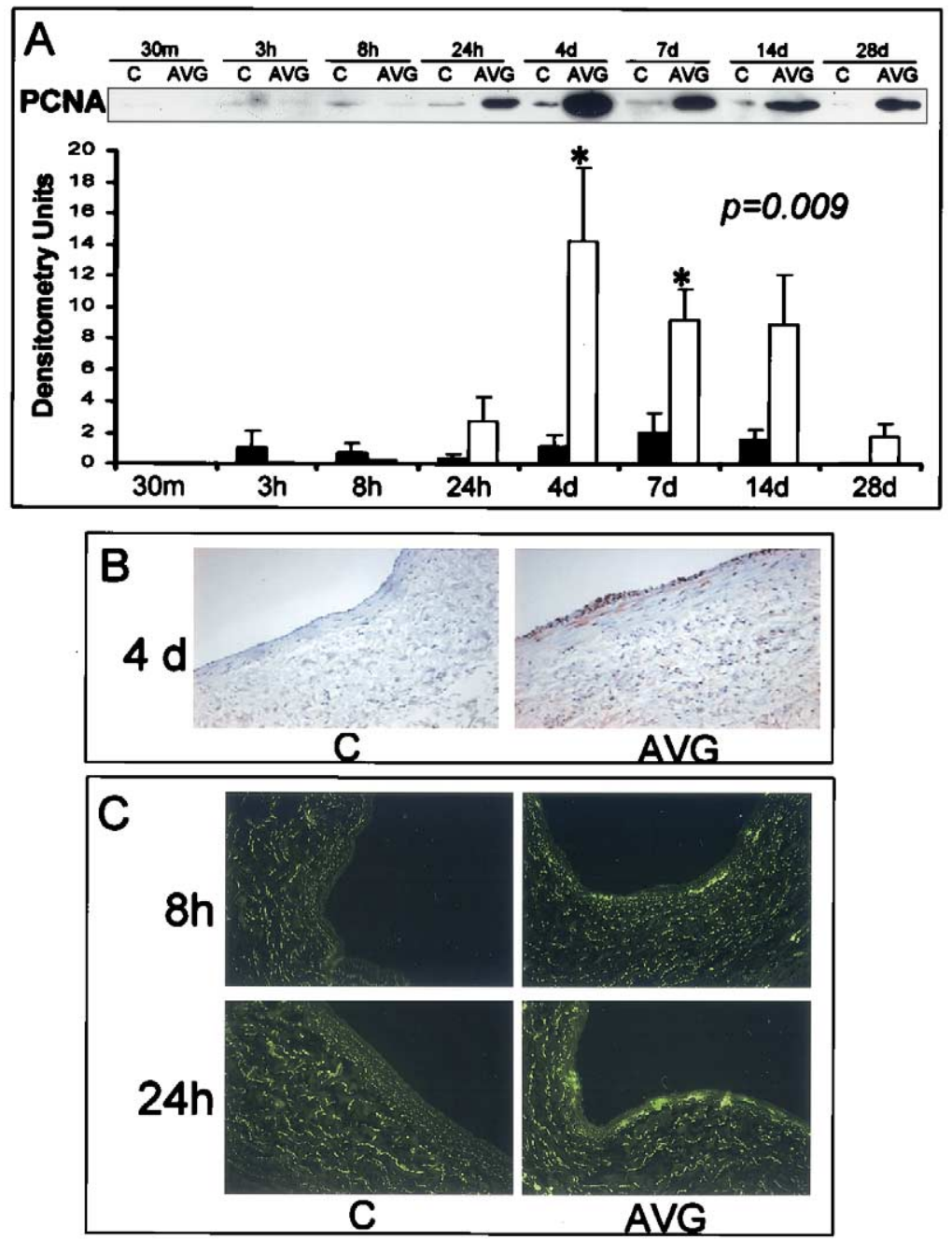

Figure 6. Vein graft arterialization induces medial and luminal cell proliferation and apoptosis. A, Representative Western blot comparing PCNA expression in contralateral external jugular vein (C) and arterialized vein graft (AVG) at the indicated time points after arterialization. Upper panel: membranes probed with anti-PCNA antibody (PCNA). Densitometric analysis of PCNA expression in contralateral external jugular veins (gray bars) and arterialized vein grafts (white bars). Means \pm SEM of 3 independent experiments are shown. Overall statistical significance is shown. Asterisk denotes significant difference from the control at each time point $(P<.05)$ via GLM parameter estimates. B, Immunohistochemical staining of PCNA in arterialized vein graft (AVG) compared with contralateral external jugular vein (C) at 4 days. C, TUNEL staining shows increased apoptosis in arterialized vein grafts (AVG) compared with contralateral external jugular veins $(C)$ at 8 and 24 hours. $(200 \times$.)

apoptosis was barely detected at later time points (data not shown). Thus, an early onset of apoptosis is accompanied by and followed by cellular proliferation.

Vein-to-Vein and Artery-to-Artery Bypass Grafting Does Not Result in MAPK Activation or PCNA Expression

To test whether the observed MAPK activation was specific to arterialized vein grafts or a nonspecific effect of vessel manipulation, EJV grafts were used to bypass the contralateral
EJV. In contrast to vein graft arterialization, vein-to-vein bypass grafting did not induce ERK-1/2 or $\mathrm{p} 38^{\mathrm{MAPK}}$ activation (Figure 7, A). Similarly, carotid arterial grafts used to bypass the contralateral carotid artery did not show MAPK activation (Figure 7, A). Similarly, no PCNA induction was detected in vein-to-vein bypass at 4 days (Figure 7, $B$ ).

\section{Discussion}

Although the literature on MAPK activation in arterial injury is extensive, to date a similar activation during vein 
graft arterialization has only been suggested by observations on mechanical stretching of cultured smooth muscle cells ${ }^{17}$ or excised vessels. ${ }^{18}$ Our study therefore represents the first characterization of MAPK activation following vein graft arterialization and indicates MAPKs as important intracellular mediators of stimuli produced during vein arterialization. In addition, our data suggest a molecular mechanism to explain differences between the type of injury that occurs in arterialized vein grafts and arterial injury, possibly elucidating how the stimuli are sensed in the 2 systems. In fact, similar to arterial injury, vein graft arterialization results in early activation of ERK-1/2 and $\mathrm{p} 38^{\mathrm{MAPK}}$, with a second activation peak observed later at 4 days. Unlike arterial injury, vein graft arterialization does not cause activation of $\mathrm{JNK}^{6}$

Previous studies combining in vivo observations and analysis of cultured vascular cells have suggested a potential role for MAPKs in vein graft intimal hyperplasia, ${ }^{19}$ and others have described cell proliferation and apoptosis after vein graft interposition in a variety of models. ${ }^{16,17,20}$ The end result of the vascular remodeling that follows vein graft arterialization is intimal hyperplasia, which ultimately leads to stenosis and reduced long-term graft patency. Although the exact sequence of molecular events leading to intimal hyperplasia has not been determined, ${ }^{1,6}$ many studies have shown that the development of vein graft stenosis involves migration and proliferation of smooth muscle cells into a neointima with abundant deposition of extracellular matrix. ${ }^{2}$ A number of approaches have been used in attempts to abolish or attenuate this medial response. ${ }^{21-23}$ However, the elucidation of the mechanisms that regulate the response of injured vessels is far from complete. To date, few studies are available on the mechanisms of intimal hyperplasia and the response to injury in vein grafts. ${ }^{20,24}$ However, the intracellular signaling in response to vascular injury following arterial balloon injury has been well characterized. ${ }^{6}$

Arterial injury results in rapid activation of ERK-1/2 and JNK. ${ }^{6}$ However, the balloon injury model has a number of limitations because it targets healthy vessels whereas clinical interventions are performed on diseased ones. In addition, because the rat carotid artery has only rare intimal cells, ${ }^{25}$ observations of the neointimal response to injury may not translate to the human. Furthermore, leukocyte infiltration is not observed in the rat model, unlike in human vein grafts and large animal models. ${ }^{25} \mathrm{We}$ found significant leukocyte infiltration in canine vein grafts in the first few hours after arterialization (Sharony et al, manuscript in preparation, 2003).

The differences in MAPK activation between vein graft arterialization and arterial balloon injury highlight the biological differences between these 2 mechanisms of injury. Therefore, it is not surprising to observe different intracellular responses in these 2 models. The vein graft has nu-
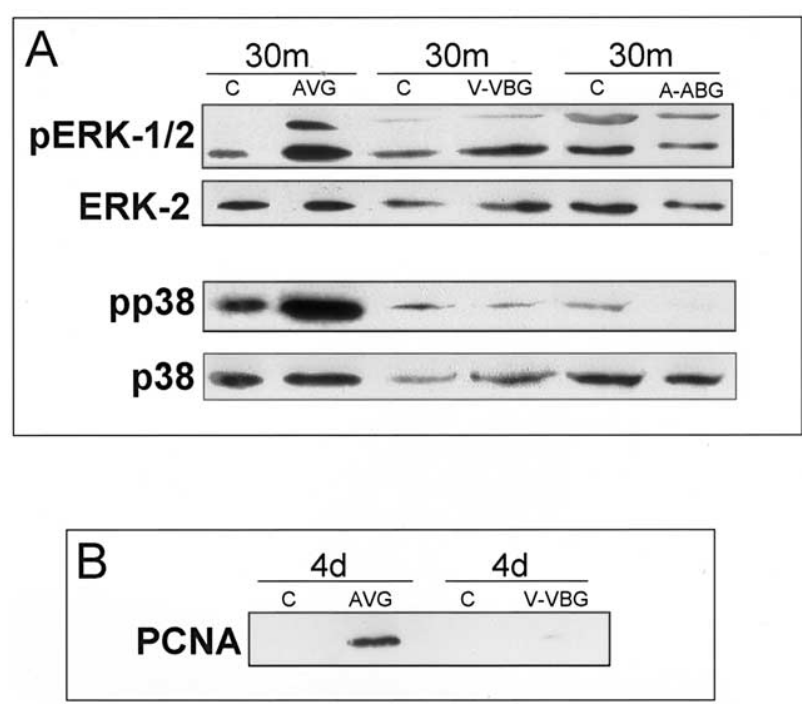

Figure 7. Vein-to-vein or artery-to-artery bypass does not induce MAPK activation or PCNA expression. A, Representative Western blot of ERK-1/2 and $\mathrm{p38}{ }^{\mathrm{MAPK}}$ activation in arterialized vein bypass grafts, vein-to-vein bypass grafts, and artery-to-artery bypass grafts at $\mathbf{3 0}$ minutes following arterialization. B, Representative Western blot of PCNA expression in arterialized vein bypass grafts and vein-to-vein bypass grafts at 4 days following arterialization. $\boldsymbol{C}$, Control (contralateral external jugular vein, femoral vein and femoral artery, respectively); $A V G$, arterialized vein graft; $V$-VBG, vein-to-vein bypass graft; $A-A B G$, artery-to-artery bypass graft.

merous anatomic differences that alter its response to vascular injury and limit its ability to adapt to arterial flow. ${ }^{5}$

A potential common feature of all vascular injuries is the increased availability of growth factors and cytokines at the site(s) of injury. These may originate from either circulating cells, from cells within the vessel wall, or both. ${ }^{26}$ Additionally, the existence of a cascade of growth factors ${ }^{27}$ affecting vascular cells suggests a potential mechanism for the observed bimodal MAPK response. ${ }^{6}$ Growth factor release also points to a role for apoptosis in vascular remodeling. Induction of apoptosis has been attempted to reduce intimal hyperplasia by decreasing the actual number of medial cells after arterial injury. ${ }^{28}$ However, cell death secondary to arterial injury has been implicated in releasing growth factors that activate medial smooth muscle cells. ${ }^{29}$ This finding points to a delicate balance of the cellular phenotypes involved in vascular remodeling after injury. We showed that release of fibroblast growth factor-2 is key to endothelial cell repair through ERK-1/2 activation ${ }^{10,11}$ and that excision and manipulation of saphenous veins being prepared for grafting results in strong activation of growth factor-dependent signaling pathways. ${ }^{15}$

Mechanical stretching associated with arterialization of vein grafts has been shown to induce MAPK activation in 
cultured smooth muscle cells ${ }^{17}$ and in excised human vessels. ${ }^{18}$ Interestingly, Curi and colleagues ${ }^{18}$ have shown that stretching can activate ERK-1/2 but not JNK, thus supporting the possibility that the observed differential activation of MAPK pathways reported here may, at least in part, be due to mechanical distention of the vein graft due to arterialization.

In light of the potential role played by MAPKs in vascular remodeling, it is of interest that incubation of harvested saphenous vein grafts in a specific mitogen-activated protein kinase kinase inhibitor effectively decreases ERK$1 / 2$ activation. ${ }^{15}$ These results prompt future investigations aimed at interfering with MAPK pathways to probe their involvement in vein graft medial proliferation and apoptosis and, ultimately, in neointima formation.

Understanding the signaling pathways involved in arterialization-induced vascular remodeling may complement surgical intervention, leading to prevention of vein graft intimal hyperplasia and, ultimately, restenosis and graft failure. Harvested saphenous vein grafts are ideal targets for molecular therapy as they are held in an isolated environment outside of the body prior to grafting. ${ }^{14}$ Specific synthetic or gene-based inhibitors could be uniquely targeted at vein grafts and achieve the desired control over the signaling pathways without systemic effects.

\section{References}

1. Angelini GD, Jeremy JY. Towards the treatment of saphenous vein bypass graft failure-a perspective of the Bristol Heart Institute. Biorheology. 2002;39:491-9.

2. Motwani JG, Topol EJ. Aortocoronary saphenous vein graft disease: pathogenesis, predisposition, and prevention. Circulation. 1998;97: 916-31.

3. Sarjeant JM, Rabinovitch M. Understanding and treating vein graft atherosclerosis. Cardiovasc Pathol. 2002;11:263-71.

4. Schwartz SM, Reidy MA, O'Brien ER. Assessment of factors important in atherosclerotic occlusion and restenosis. Thromb Haemost. 1995;74:541-51.

5. Dobrin PB. Mechanical factors associated with the development of intimal and medial thickening in vein grafts subjected to arterial pressure. A model of arteries exposed to hypertension. Hypertension. 1995;26:38-43.

6. $\mathrm{Hu} \mathrm{Y}$, Cheng L, Hochleitner BW, Xu Q. Activation of mitogenactivated protein kinases (ERK/JNK) and AP-1 transcription factor in rat carotid arteries after balloon injury. Arterioscler Thromb Vasc Biol. 1997;17:2808-16.

7. Widmann C, Gibson S, Jarpe MB, Johnson GL. Mitogen-activated protein kinase: conservation of a three-kinase module from yeast to human. Physiol Rev. 1999;79:143-80.

8. Marshall CJ. Specificity of receptor tyrosine kinase signaling: transient versus sustained extracellular signal-regulated kinase activation. Cell. 1995;80:179-85.

9. Bornfeldt KE, Campbell JS, Koyama H, et al. The mitogen-activated protein kinase pathway can mediate growth inhibition and proliferation in smooth muscle cells. Dependence on the availability of downstream targets. J Clin Invest. 1997;100:875-85.

10. Pintucci G, Steinberg BM, Seghezzi G, et al. Mechanical endothelial damage results in basic fibroblast growth factor-mediated activation of extracellular signal-regulated kinases. Surgery. 1999;126:422-7.

11. Pintucci G, Moscatelli D, Saponara F, et al. Lack of ERK activation and cell migration in FGF-2-deficient endothelial cells. FASEB J. 2002;16:598-600.

12. Watson L, Herdegen T, Buschmann T, et al. JNK and c-Jun but not ERK and c-Fos are associated with sustained neointima-formation after balloon injury. Eur J Clin Invest. 2000;30:11-7.

13. Izumi Y, Kim S, Namba M, et al. Gene transfer of dominant-negative mutants of extracellular signal-regulated kinase and c-Jun NH2-terminal kinase prevents neointimal formation in balloon-injured rat artery. Circ Res. 2001;88:1120-6.

14. Fernandez HA, Kallenbach K, Seghezzi G, et al. Inhibition of endothelial cell migration by gene transfer of tissue inhibitor of metalloproteinases-1. J Surg Res. 1999;82:156-62.

15. Bizekis CS, Pintucci G, Derivaux CC, et al. Activation of mitogenactivated protein kinases in human saphenous vein for aortocoronary bypass grafting: modulation by a synthetic inhibitor. J Thorac Cardiovasc Surg. 2003;126:659-65.

16. Rodriguez E, Lambert EH, Magno MG, Mannion JD. Contractile smooth muscle cell apoptosis early after saphenous vein grafting. Ann Thorac Surg. 2000;70:1145-53.

17. Mayr M, Li C, Zou Y, Huemer U, Hu Y, Xu Q. Biomechanical stress-induced apoptosis in vein grafts involves p38 mitogen-activated protein kinases. FASEB J. 2000;14:261-70.

18. Curi MA, Skelly CL, Meyerson SL, et al. Differential mechanical activation of mitogen-activated protein kinases in intact human blood vessels. J Surg Res. 2002;108:198-202.

19. Xu Q. Biomechanical-stress-induced signaling and gene expression in the development of arteriosclerosis. Trends Cardiovasc Med. 2000;10: 35-41.

20. Shi Y, O'Brien JE Jr, Mannion JD, et al. Remodeling of autologous saphenous vein grafts. The role of perivascular myofibroblasts. Circulation. 1997;95:2684-93.

21. Newby AC, Baker AH. Targets for gene therapy of vein grafts. Curr Opin Cardiol. 1999;14:489-94.

22. Kibbe MR, Billiar TR, Tzeng E. Gene therapy for restenosis. Circ Res. 2000;86:829-33.

23. Lijnen HR, Soloway P, Collen D. Tissue inhibitor of matrix metalloproteinases-1 impairs arterial neointima formation after vascular injury in mice. Circ Res. 1999;85:1186-91.

24. Landymore RW, Kinley CE, Cameron CA. Intimal hyperplasia in autogenous vein grafts used for arterial bypass: a canine model. Cardiovasc Res. 1985;19:589-92.

25. Schwartz SM, deBlois D, O'Brien ER. The intima. Soil for atherosclerosis and restenosis. Circ Res. 1995;77:445-65.

26. Waltenberger J. Modulation of growth factor action: implications for the treatment of cardiovascular diseases. Circulation. 1997;96:408394.

27. Seghezzi G, Patel S, Ren CJ, et al. Fibroblast growth factor-2 (FGF-2) induces vascular endothelial growth factor (VEGF) expression in the endothelial cells of forming capillaries: an autocrine mechanism contributing to angiogenesis. J Cell Biol. 1998;141:1659-73.

28. Steg PG, Tahlil O, Aubailly N, et al. Reduction of restenosis after angioplasty in an atheromatous rabbit model by suicide gene therapy. Circulation. 1997;96:408-11.

29. Lindner V, Reidy MA. Proliferation of smooth muscle cells after vascular injury is inhibited by an antibody against basic fibroblast growth factor. Proc Natl Acad Sci U S A. 1991;88:3739-43. 